\title{
An Opportunity To Help
}

A report of the NNV sponsored meeting held on 26-27 May in Amersfoort, The Netherlands, of the organizing committee for an east/west meeting outlines how EPS members may be able to help eastern colleagues. News and views about other approaches will be sought.

In response to the urgent need to act decisively on ways to help physicists in eastern Europe, Council in Uppsala accepted a proposal made by A.M. Hoogenboom on behalf of the Netherlands' Physical Society (NVV) to host a meeting of an organizing committee for an additional session at this year's General Conference in Amsterdam aimed at tackling the problem. The generosity of the Stichting Physica and the Netherlands' society allowed representatives from eastern European physical societies to discuss alternatives for two days in late May in Amersfoort with colleagues from the EPS and from the German and British societies.

A report of the meeting was prepared by the secretary, E.W.A. Lingeman, Chairman of the EPS Action Committee for Physics and Society, for the President of EPS, Professor Ricci. The report has been sent to the Presidents of all member societies who have been asked to make it available to their own members.

Professor Ricci has accepted the committee's recommendation that the report and its conclusions should form the basis of discussions during the General Meeting in Amsterdam on how EPS can act. Members will be urged to contribute any ideas and important supplementary information, on both existing initiatives and alternative opportunities, in preparation for setting up a plan of action.

This summary of the report overviews the current situation in the east of science in general and physics in particular, before outlining the committee's principle recommendations.

\section{REPORT}

\section{General Background}

E.W.A. Lingeman, who organized the meeting, set the background to the discussions by summarizing his understanding of how physics functioned in eastern Europe. Centrally planned socialism shaped the scientific establishment on the Soviet model. Research is carried out in the Universities (the region has about 55 ) and in an extensive network of Institutes (Poland: 81; Czechoslovakia: 12; Hungary: 36; Romania: 44$)$ that were historically either subordinated to the Academy of Sciences or controlled by government ministries. The Presidium of the Academy of Sciences was meant to coordinate research but the Academy's powers were often curtailed by a government body, usually a State Commission for Science and Technology.

At the supranational level, a country's R. and $D$. plans since 1985 were at least nominally tied to those of its COMECON partners via a Comprehensive Programme.

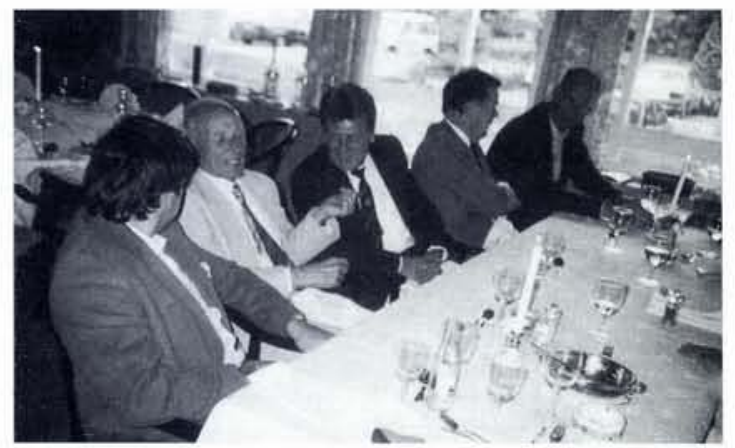

The NVV sponsored organizing committee for an east/west meeting relaxes. From left to right: - upper: F. Mezei (Hungary), O.G. Folberth (Germany), M. Ivascu (Romania), M.G. Ebison (United Kingdom), B. Kuiper (CERN);

- lower: E.W.A. Lingeman (The Netherlands), E. Skrzypczak (Poland), I. Abonyi (Hungary), J. Zofka (Czechoslovakia), G. Thomas (EPS).

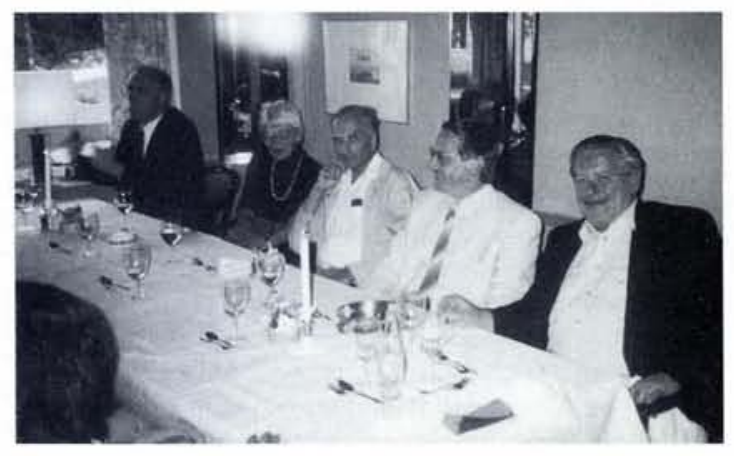

The system afforded individual physicists a measure of security, although salaries, especially at junior levels, were often very low. Jobs were assured and professional life for the majority did not demand strong political allegiances. But working conditions were difficult owing to economic constraints compounded by some political restrictions. Hard currency to buy world class journals, books, materials and equipment was lacking, travelling to meetings was a luxury, ownership of potentially subversive equipment such as photocopiers was controlled. Telephone systems functioned inadequately and computer networks were often nonexistent to the extent that it will take Romania five years to start up an EARN general purpose computer network for research and education. Western governments were partly at fault because they controlled the exportation of computer technology.

\section{Physics in Eastern Europe}

While each of the eastern countries should be viewed separately, some general themes persist. In summaries of the state of physics by the representatives of five eastern European physical societies, M. Ivascu from the Institute of Atomic Physics, Bucharest emphasized that basic research was often discouraged and in the worst cases suppressed, with research in Romanian institutes being directed solely towards engineering problems. Paradoxically, applied physics research also tended to be weak because industry itself was generally in a poor shape and, according to J. Zofka of the Institute of Nuclear Physics, Rez $U$ Prahy, Czechoslovakia, was skeptical of the value of having physics and physicists in its laboratories. Not unsurprisingly, few physicists are employed in industry.

But international contacts did exist with groups throughout eastern Europe participating in various projects in physics re- search all over Europe, notably at the major centres. The wish to collaborate was strong but finding the necessary funds was difficult unless special arrangements were negotiated. E. Skrzypczak from the Institute of Experimental Physics, University of Warsaw noted that Polish collaborations were structured in such a way that they entailed little or no direct financial contribution from Poland.

Each country had a semblance of a physical society, some of which were autonomous and venerable institutions. I. Abonyi from the Department of Theoretical Physics, Eötvös University, Budapest pointed out that the Hungarian society - called the Roland Eötvös Physical Society after its founder - is nearly 100 years old and has always been independent of the Academy of Sciences (which itself is independent of the Government). However, most national societies were tied, either financially or administratively and sometimes both, to the Academies. All the eastern societies received important contributions from the State, either indirectly as was Hungary's case through its membership of the Federation of Scientific and Technical Societies, or directly from the Academy who controlled a society's budget.

The national societies publish a variety of journals, sometimes in English or with English versions (Czechoslovak Journal of Physics, Acta Physica Polonica, Progress in Physics - a review journal for non-physicists) catering to a wide readership. Meetings of all sorts are held, but only in isolated cases were these not controlled directly by the government. Some of the societies take turns at sponsoring and organizing the Physics Olympiad. They also run similar competitions at the national level in addition to preparing students for the Olympiad.

Exchange schemes, mostly bilateral, short term and for young physicists to facilitate both working contacts and meetings' 
attendance, are promoted, managed and financed. These usually involve other eastern countries. However, both the Hungarian society and Czechoslovakian society - which exists as the Czech and Slovak Sections of the Union of Czechoslovak Mathematicians and Physicists founded 125 years ago - have exchange agreements with two western societies (the Austrian and German). The German society also maintains an agreement with Poland. Some societies have been able to help meet travel costs to conferences over an above commitments under the agreements.

Consultation activities seemed to be rare with only the Hungarian society reporting that it used to help find people to carry out research in industry.

\section{The Changes... Some Negative}

Much has already happened in the wake of the accelerating transition to some form of market economy with political representation. The macroscopic and microeconomic effects are all too obvious: economies in disarray, surging inflation, looming unemployment, weighty foreign debts, steeply rising travel costs, cuts in real terms of budgets for research and teaching in Hungary, the end of assured government funding for sectorial institutes in Poland, no indication of the amount of government funding for research in Romania.

Restructuring of research will probably bring about significant redeployment and maybe unemployment. O.G. Folberth, the President of the German Physical Society speaking about the situation in the Democratic Republic of Germany - which remains very much a case apart - foresaw problems with the Rossendorf Research Institute where many scientists will probably have to be retrained. Czechoslovakia is forecasting that it will be necessary to boost the number of physicists employed in industry by $10 \%$ to absorb people displaced from the Institutes.

A consequence of restructuring is that the "wrong" people are still being approached by well-intentioned western officials; this can lead to considerable bitterness. By the same token, physicists and officials newly appointed in the east to positions involving international affairs such as exchange schemes sometimes do not know with whom to deal in the west.

Redefining scientific objectives and sharing resources fairly in a deteriorating economic climate is creating headaches. I. Abonyi made it clear that much work remains in establishing a democratic, respected and unprejudiced system to manage science.

The physical societies are under considerable financial pressure. In the face of actual or impending reductions in state subventions and industrial contributions (if any), the societies cannot raise rapidly their membership fees as these become a more important (and perhaps the only short-term) source of income. Fees already represent a relatively high percentage of a physicist's salary, which may be as low as \$US 25 monthly in Poland. The societies are thus finding it difficult to meet the rising cost of their publications as the number of subscriptions decreases (Poland's Progress in Physics is presently not being published for lack of money).

Also at risk are some common initiatives such as the Physics Olympiad, the financing of which by governments is no longer assured. I. Abonyi mentioned the problem of funding even well established and successful international conferences such as the Middle European Collaboration (MECO), where the host country must meet expenses.

Generating funds to cover travel costs involved in the exchange agreements, in the face of a rising and only partially satisfied demand, was a cause for concern everywhere. Awareness of the problems does not seem to be overwhelming because a recent international appeal by the Polish society for help to improve student exchange evoked a very poor response.

The move towards the application of value added taxes (VAT) will reduce the societies' income further. The Hungarian representative reported that a recently introduced VAT rate of $25 \%$ on services was affecting income from conferences.

\section{... But Many Positive}

Responsibility reclaimed: E.W.A. Lingeman pointed out in his report of the meeting that the eastern European scientific community has, broadly speaking, moved to reclaim responsibility for itself. Disgraced members of the Academies have been reinstated, dubious scientific honours revoked, and the statutes of Academies and Universities redrafted on the basis of "scholarly autonomy".

Management of science: There is considerable interest in western models for managing science. This prompted M.G. Ebison, the Deputy Executive Secretary of The Institute of Physics to describe the organization of research and its funding in the UK. Romania envisages bringing its Institutes under the Ministry of Science; other countries seem to be gradually evolving new structures.

Some changes to the old system are already apparent in that scientific and academic councils are being established in the Institutes and Universities so that the latter can establish their own scientific strategies. Rigid planning of research by the Academies is being reduced. J. Zofka thought that the Academies will instead only assume a coordinating, consultative role in unifying their honorary members (the Academicians) in learned societies.

Independent societies: Another benefit of restructuring is that the national societies are now free of most official barriers and are able to handle their own affairs. In the case of Romania, this has entailed the creation (a few months ago) of a new physical society representing all branches of physics. The changes have allowed initiatives hitherto unthinkable such as the creation by the Czechoslovakian society of a new category of member, namely foreign members. It is open to physicists who left the country and work elsewhere but seek to retain ties through participation in the society's events, especially its general conference.

Independent advice: Unlike former times, international experts are presently encouraged in some east European countries (notably Czechoslovakia) to serve on academic and scientific councils and boards.

Freer travel: Perhaps the most visible symbol of the new freedom is the lifting of travel restrictions (physicists in Romania were formerly granted only 20 visas each year). Unfortunately, the economic situation and rising travel costs are limiting opportunities.

Computer networking: A contribution to the report by F. Greisen from CERN spoke of how the US Department of Commerce has recently specified the conditions under which eastern countries can be connected to the EARN computer network. This is important since the USA, which ships most of the so-called supercomputers used in networks, requires a Supercomputer Safeguard Plan (SSP) specifying that a machine will not be used by a COCOM proscribed country. COCOM is a government committee comprising NATO countries, Japan and Australia charged with regulating the export of strategic technology. The effect of the new ruling is that Poland will soon be officially linked to EARN via a line, ordered in May 1990, from Warsaw University to UNI-C in Denmark.

The EARN Board that supervises the EARN network has up to now turned down all formal applications for east European connections. Contacts were nonetheless maintained with a number of institutions that already possess some of the essential equipment and software. Generally speaking, new countries can be connected immediately once a line is delivered. EARN works on the basis that each country must have one international node connected to any other country, and that it must finance installations at both ends of the connecting line.

At the institute level, physicists in eastern Europe cooperating with colleagues in the west are pressing hard for improved data communication services. J.J. Thresher, the Director for Computing at CERN, in an addendum to the report outlined a possible strategy for the organization given the many constraints. The best solution seems to the installation of a single line between CERN and each eastern country, with controls on access: network connections would then be set up at either end.

Programmes extended: B. Kuiper from CERN described how the organization's Associates Programme in favour of young post-graduates from eastern European countries has been extended in 1990 and 1991. The hope is that European Community and other international programmes will also be enlarged.

New initiatives: A large and ever increasing number of proposals are being made for stimulating physics research and teaching. They range from global initiatives involving 
the creation of International Universities in Czechoslovakia, joint programmes and laboratories based on local strengths, and programmes to encourage individual researchers trained abroad to return home. Education and training: E. Skrzypczak believed that a new task for the physical societies lay in reinstating and strengthening the relationship between physics and industry.
Meanwhile, discussions are underway to modernize the physics curriculum, especially in the light of falling student numbers owing to the scarcity of assured jobs. In Czechoslovakia, some graduate students have been moved from university departments to the generally much better equipped Institutes to carry out their thesis research.

\section{RECOMMENDATIONS}

Data base of physicists: Generate a confidential data base of reliable physicists and officials (from both east and west) who are either candidates for peer review committees, councils and advisory boards or who are appropriate organizational contacts. The committee strongly recommended the first, namely that EPS makes available a detailed listing of physicists who are willing to serve on panels and help in peer review.

Computer networks: EPS should help eastern countries become connected to European computer networks. It was recommended that assistance is given to connect mainframe computers in institutes to existing networks, especially EARN.

Science policy and management: Promote the efficient restructuring of physics by informing physicists on how research is managed, financed, guided and structured in western Europe. The recommendation was that EPS collect and disseminate the appropriate information.
Exchange schemes: Consolidate information about exchange schemes (especially for students), and propose ways to promote the formation of new schemes or the extension of existing ones. EPS already acts in a limited way as a clearing house for student exchanges. The recommendation was that a larger amount of information should be made more easily available.

Journal inventory: Assess the situation of journals (and in a qualitative way that of books) in scientific libraries so that EPS may formulate a solution to the problems of missing volumes (cancelled subscriptions) and an inadequate number of subscriptions. The committee recommended that the national societies be asked to make an inventory of cancelled library subscriptions going back 10 years.

Scientific equipment: Create an easily accessible data base of redundant (but not obsolete!) scientific equipment. The committee recommended the creation and maintenance of a computer data base, accessible on networks, of this equipment.

\section{AARHUS UNIVERSITY, DENMARK}

At the Institute of Physics, Aarhus University, Denmark, a post is open as a Professor of Experimental Physics from 1 July 1991.

The candidate must be able to strengthen research in experimental physics and participate in education and, independently as well as in co-operation with colleagues at the Institute, be able to contribute to the utilization of ISA, the new storage ring, in research.

The storage ring, which is located at the Institute of Physics, offers outstanding possibilities for atomic physics and quantum optical studies with stored ions and, furthermore, can be used for atomic and solid state physics investigations using synchrotron radiation (below $10 \mathrm{KeV}$ ).

Apart from information and documentation of the professional and educational qualifications of the candidate, the application should contain future research plans, particularly in relation to the storage ring.

The application should include copies (in triplicate) of published papers which the applicant wishes to be considered by the selection committee. The full evaluation of the committee will be forwarded to all the applicants.

Further information may be obtained from:

Prof. Jens Ulrik Andersen, Institute of Physics, Ny Munkegade, DK-8000 Aarhus C, Denmark - telephone: ++45 (86) 128899.

Applications should be addressed to the Queen of Denmark and sent to:

Aarhus University, Ndr. Ringgade 1,

DK-8000 Aarhus C, Denmark

and marked $211 / 5-1$. The deadline for the receipt of all application material is 14 September 1990 at 12.00 .

\section{NEXT STEP}

The committee's recommendations are not final. But they are thought to be realistic and capable of yielding significant benefits fairly quickly. Members will have the opportunity at the General Assembly in Amsterdam in September to express their own views about the opportunities, fill in whatever important information is lacking, and propose alternative initiatives. Professor Ricci will then develop a plan for action, bearing in mind that it will have to be taken up by volunteers.

\section{Mathematica A System for Doing Mathematics by Computer}

A Wolfram Research Inc. product

$\square$ Numerics - Works with numbers of arbitrary magnitude and precision.

$\square$ Symbolics - Encyclopaedia of mathematical functions and operations used in arithmetic, algebra and analysis.

Procedural, functional and mathematical programming.

$\square$ Graphics - 2D, 3D and animated PostScript graphics.

Text processing - Fully interactive reports and textbooks.

Runs on - MS-DOS based computers; Macintosh, Apollo, Hewlett Packard, IBM AIX/RT, MIPS, Silicon Graphics, Sony, Sun, VAX.

Now available in Europe from:

MathSoft Overseas, Inc.

POB 641, 1211 Geneva 3, Switzerland

Tel. ++41 (22) 465260

Fax $++41(22) 465939$

\section{FOC Hard Hit}

A preliminary report to NASA by the Space Telescope Science Institute, Baltimore, MD that selects and supports users of the Hubble Space Telescope gives an estimate of the impact of the instrument's defective mirror on its scientific capabilities. Some $80-90 \%$ of the programmes for the Wide Field and Planetary camera are "deferred" meaning that they can be carried out after installation of a new camera (scheduled for 1993) with a corrector lens. About $50 \%$ of programmes of the Faint Object Camera built by ESA are lost; those that remain need a threefold increase in observing time and there is no possibility of recovering capabilities in the future. Regarding the spectrographs: the optical part of the Faint Object Spectrograph is no longer comparable with ground facilities but the UV part remains unique and serviceable. Including the High Resolution Spectrograph, about $20 \%$ of programmes are lost. For the High Speed Photometer, $10-20 \%$ of the photometric programmes are lost but all the observational capabilities remain.

The STSI will be contacting principal investigators among the general observers at the end of August 1990 for comments before making final recommendations to the committee responsible for allocating observation time. A final detailed report will be submitted to NASA within 4-5 months. 